\title{
Echocardiographic features of tropical endomyocardial disease in South India
}

\author{
G VIJAYARAGHAVAN, J DAVIES, ` S SADANANDAN, C J F SPRY, D G GIBSON, \\ J F GOODWIN
}

From Medical College Hospital, Trivandrum, Kerala, India; Departments of Immunology and Medicine, Royal Postgraduate Medical School, London; and Department of Cardiology, The Brompton Hospital, London

SUMMARY Fifteen patients with tropical endomyocardial disease which had been proved angiographically were studied using $\mathbf{M}$-mode and cross-sectional echocardiography to determine the extent to which specific features of this disease could be recognised by these non-invasive methods. Tethering of the posterior mitral valve leaflet to the ventricular wall in combination with areas of echo-dense material in the posterior left ventricular wall and associated papillary muscle appeared to be a constant diagnostic feature of this disease. Colour coding of regional echo amplitude showed high intensity echoes in a distribution corresponding closely to that of the fibrosis known to occur in this condition. Though $\mathrm{M}$-mode echocardiography did not contribute diagnostic information, it was useful in defining the functional consequences of myocardial or mitral valve disease. Digitisation of records allowed a restrictive pattern of left ventricular filling to be observed. It was concluded that cross-sectional echocardiography, particularly when supplemented by colour coded amplitude processing, can make a confident non-invasive diagnosis of tropical endomyocardial disease and so could be useful in assessing its progression or response to treatment.

Tropical endomyocardial disease ${ }^{1}$ gives rise to a restrictive cardiomyopathy with left and/or right sided heart failure. Several studies of this condition as it occurs in the tropics ${ }^{2-4}$ and in temperate areas ${ }^{5-7}$ have shown $M$-mode echocardiography to be of limited value in making the diagnosis. Only nonspecific abnormalities such as left atrial enlargement and abnormal ventricular wall motion have been described and there appears to be little correlation of posterior left ventricular wall thickness as measured by $M$-mode studies and the severity of endomyocardial fibrosis. More specific diagnostic abnormalities have been defined in patients with eosinophilic endomyocardial disease by cross-sectional echocardiography, and these abnormalities have been confirmed by angiography or surgery. ${ }^{7}$

The present study was performed in order to assess the role of echocardiography in the diagnosis of tropical endomyocardial fibrosis. In particular, the sensitivity of cross-sectional echocardiography in defining sites and severity of the disease was assessed by

^Present address: Royal Gwent Hospital, Newport, Gwent NP4 OYP.

Accepted for publication 19 May 1983 comparing echocardiographic findings with angiography in a group of previously studied subjects. The possibility was investigated that echocardiography alone is sufficient to make a confident diagnosis of endomyocardial fibrosis which would allow these techniques to be used to assess disease extent and evolution, and to isolate early disease activity noninvasively during life.

\section{Subjects and methods}

Fifteen patients with endomyocardial fibrosis were studied at Trivandrum Medical College Hospital, Kerala, India. All had undergone angiocardiography and in two the histological diagnosis had been made by cardiac biopsy. All patients were in an advanced stage of their disease on clinical and haemodynamic grounds (Table 1). Biventricular disease had been shown angiographically in six patients (cases 1 to 6). Three patients (cases 7 to 9 ) had left ventricular disease only, and in the remaining six patients (cases 10 to 15 ) it was confined to the right. In case 9 , however, a normal right ventriculogram was accompanied by a right ventricular endomyocardial biopsy diagnostic of endomyocardial fibrosis. 
Table 1 Summary of distribution of abnormalities seen in 15 patients with endomyocardial fibrosis

\begin{tabular}{|c|c|c|c|c|c|}
\hline \multirow{2}{*}{$\begin{array}{l}\text { Case } \\
\text { No. }\end{array}$} & \multirow[t]{2}{*}{ Age (y) } & \multirow[t]{2}{*}{$\operatorname{Sex}$} & \multirow[t]{2}{*}{ Duration of cardiac symptoms (y) } & \multicolumn{2}{|c|}{ Sites of lesions in angiocardiograms } \\
\hline & & & & Right ventricle & Left ventricle \\
\hline $\begin{array}{r}1 \\
2 \\
3 \\
4 \\
5 \\
6 \\
7 \\
8 \\
9 \\
10 \\
11 \\
12 \\
13 \\
14 \\
15\end{array}$ & $\begin{array}{r}19 \\
48 \\
8 \\
14 \\
5 \\
25 \\
35 \\
27 \\
13 \\
21 \\
33 \\
5 \\
13 \\
36 \\
14\end{array}$ & $\begin{array}{l}\mathbf{M} \\
\mathbf{F} \\
\mathbf{M} \\
\mathbf{M} \\
\mathbf{F} \\
\mathbf{F} \\
\mathbf{M} \\
\mathbf{F} \\
\mathbf{M} \\
\mathbf{F} \\
\mathbf{M} \\
\mathbf{M} \\
\mathbf{F} \\
\mathbf{F} \\
\mathbf{M}\end{array}$ & $\begin{array}{l}4 \\
5 \\
3 \\
5 \\
3 \\
2 \\
2 \\
5 \\
1 \\
1 \\
4 \\
4 \\
5 \\
8 \\
5\end{array}$ & $\begin{array}{l}+ \\
+ \\
+ \\
+ \\
+ \\
+ \\
+ \\
- \\
+ \\
+ \\
+ \\
+ \\
+ \\
+ \\
+\end{array}$ & $\begin{array}{l}++ \\
+f \\
+ \\
+ \\
+ \\
+\neq \\
++ \\
++ \\
+ \\
+ \\
= \\
= \\
= \\
-\end{array}$ \\
\hline
\end{tabular}

$\star$ Fibrosis discovered on endomyocardial biopsy.

† Mitral regurgitation.

¥Dilated poorly contracting left ventricle.

Normal subjects from the same social background as these patients, matched with regard to age and sex, were also examined clinically and studied noninvasively by echocardiography. These control subjects appeared to have slightly smaller end-systolic ( 2 to $3.6 \mathrm{~cm})$ and end-diastolic $(2.8$ to $4.5 \mathrm{~cm})$ diameters than European controls, though other values were similar to those seen in the West.

M-mode echocardiograms were recorded with an ATL Mark 3 echocardiograph (Advanced Technology Laboratories, Washington) at a paper speed of $100 \mathrm{~mm} / \mathrm{s}$ on an instantaneous dry silver paper strip chart recorder (Honeywell LS6). A $3 \mathrm{MHz}$ transducer was focused at $10 \mathrm{~cm}$. Patients were positioned in the left lateral decubitus position. Normal values were taken from average measurements obtained from local control subjects and these results were compared with previously published data. ${ }^{8}$ Echocardiograms were digitised ${ }^{10}$ and the following measurements made:

(1) End-diastolic (Dd, synchronous with the Q wave) and minimum (Ds) left ventricular dimensions, from which fractional shortening was derived as (Dd-Ds)/(Dd).

(2) Peak velocity of circumferential fibre shortening (normal range 2.0 to $3 \cdot 0 / \mathrm{s}$ ).

(3) Peak rate of dimension increase during filling (normal range 12 to $20 \mathrm{~cm} / \mathrm{s}$ ).

(4) Duration of rapid filling (normal 160 to $220 \mathrm{~ms}$ ). This period extends from the onset of the dimension increase at the start of diastole to the time when the first differential with respect to time falls below $20 \%$ of its peak value.

Cross-sectional echocardiography was performed with an ATL Mark III (Advanced Technology Laboratories, Washington) sector scanner using a 3.35 $\mathrm{MHz}$ transducer and a $45 \mathrm{~dB}$ logarithmic grey scale compression. An internally derived grey scale was superimposed on each display. Standard views were used in all cases. ${ }^{11}$ The left ventricle was studied mainly from the parasternal long and short axis views and from the apex. The right ventricle was best imaged from the apical and subcostal windows.

Colour image processing of cross-sectional echocardiograms was performed as previously described ${ }^{12}$ using a Brompton Encoder (Alltek Hospital Supplies). The colour sequence: black, cyan, green, yellow, red, magenta, blue, and white (Fig 1) represented increasing relative echo amplitude. Zero amplitude was taken as black. Parietal pericardium immediately behind the posterior left ventricular wall on the parasternal long axis view was used as an internal standard. The gain control of the echocardiograph was adjusted with the record being made to display parietal pericardium as a continuous white structure, and was kept unchanged for the remainder of the examination. Stop frame end-diastolic images were photographed using a Nikon FM $35 \mathrm{~mm}$ camera and Kodak ECK64 film. Black and white colour coded echo slides were projected simultaneously on a screen and the regional echo intensity assessed from the dominant colour of individual structures and expressed as a percentage, white being $100 \%$. A processed image, parasternal long axis view of a normal heart, one of the control subjects examined in this study, is shown in Fig. 2.

\section{Results}

\section{M-MODE ECHOCARDIOGRAM}

A summary of the M-mode echocardiographic findings is shown in Table 2. Minor abnormalities were detected in all patients, but none was specific for 


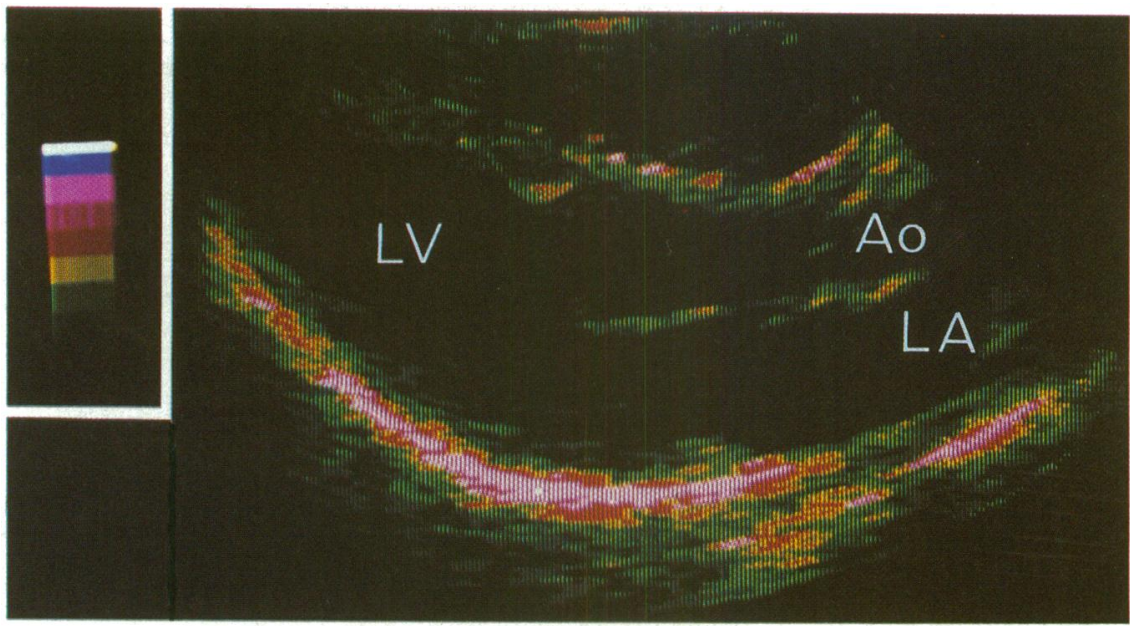

Fig. 1 (Inset) Standard colour coded scale used for all measurements. The colour sequence: black, cyan, green, yellow, red, magenta, blue, and white represented increasing relative echo amplitude. For measurement, zero amplitude was taken as black and maximum amplitude as white. In each recording the gain control of the encoder was adjusted to the minimum value at which the pericardium immediately beneath the left ventricular posterior wall appeared as a continuous white structure on the final display.

Fig. 2 A processed image parasternal long axis view of a normal heart (one of the controls used in this series). Ao, aorta; $L V$, left ventricle; $L A$, left atrium.

endomyocardial fibrosis. Right ventricular dimension was increased in seven patients (Fig. 3) and pericardial effusions were noted in two patients (Fig. 3). Septal motion was reversed in five (Fig. 3). An abnormal increase in posterior wall thickness at enddiastole was detected by $M$-mode echocardiography in only four patients. Left atrial cavity size was enlarged in three patients, all of whom had clinical evidence of mitral regurgitation. Six patients, five of whom were children below 14 years of age, had left atrial dimensions which were very small. Four patients had an exaggerated movement of the interventricular septum with sharp, sudden cessation of anterior movement in early diastole (Fig. 4).

\section{DIGITISED RECORDS}

As shown in Table 3, peak velocity of circumferential fibre shortening and fractional shortening were grossly reduced in one patient. Three others had reduced volumes of fractional shortening, suggesting some impairment of systolic function. All patients with high peak rates of circumferential fibre shortening were known to have mitral regurgitation clinically. The peak rate of filling was reduced in eight patients and the duration of rapid filling was shortened in nine. When corrected with age and sex matched control adults and children, most patients still appeared to have reduced end-systolic and enddiastolic diameters. Two patients had much enlarged end-systolic and end-diastolic diameters compatible with grossly impaired function (Fig. 5). The rate of systolic thickening was reduced in five patients and the rate of diastolic thinning was reduced in almost all (12 out of 15).

\section{CROSS-SECTIONAL ECHOCARDIOGRAMS}

Grey scale display

The most striking consistent abnormality was that in all patients studied the posterior mitral valve leaflet was thickened and appeared to be tethered down to the left ventricular posterior wall. Frequently mobility appeared to be reduced during diastole. Pericardial effusions were shown in eight patients. The posterior left ventricular wall was thickened in three patients and papillary muscle enlargement was seen in four patients. The apex of the right ventricle was thickened and deformed in 13 patients, and in four patients posterior displacement and a dimple at the tip of the ventricular apex was well seen in subcostal views. Enlargement of the left atrium was seen in four patients: nine patients had large right atrial cavities and in five patients this enlargement was continuous with a small deformed right ventricle with little or no tricuspid valve, making the whole right side appear as a single chamber.

\section{Colour-coded images}

This technique showed a wide range of abnormalities 
Table 2 Summary of M-mode echocardiograms in 15 patients with endomyocardial fibrosis

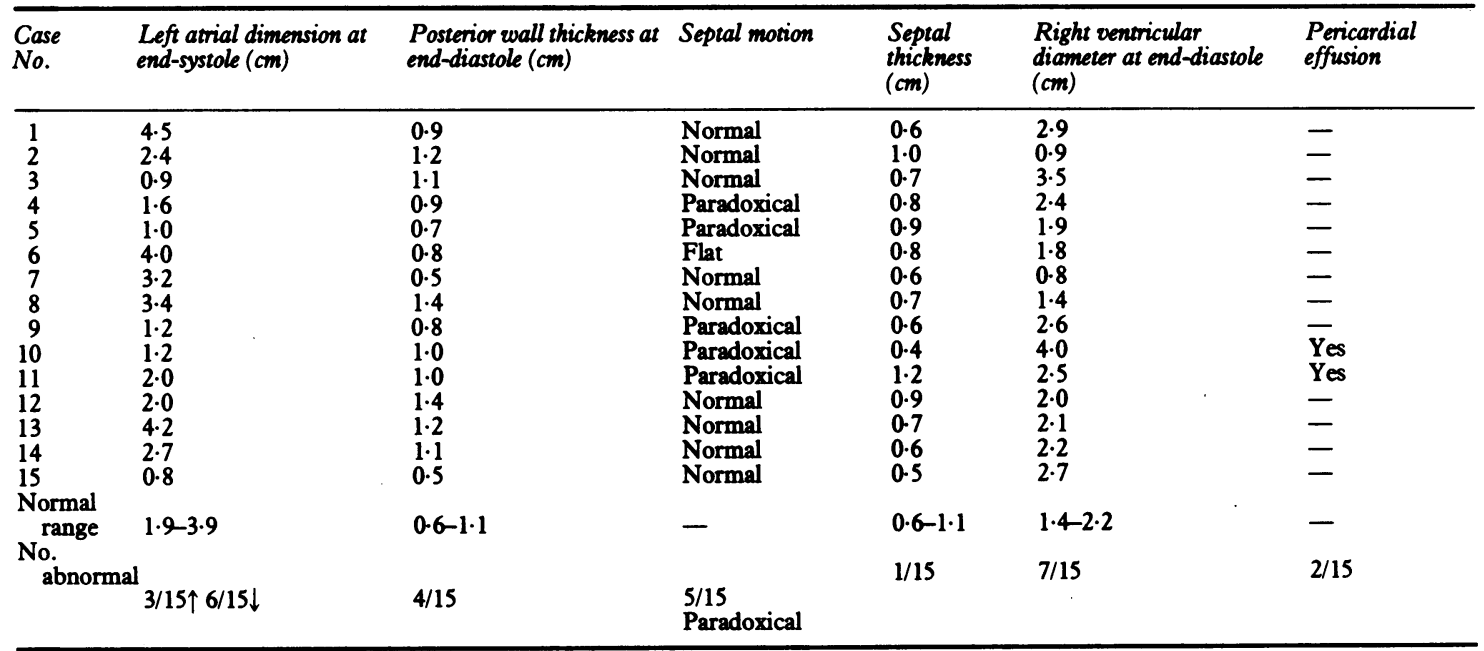

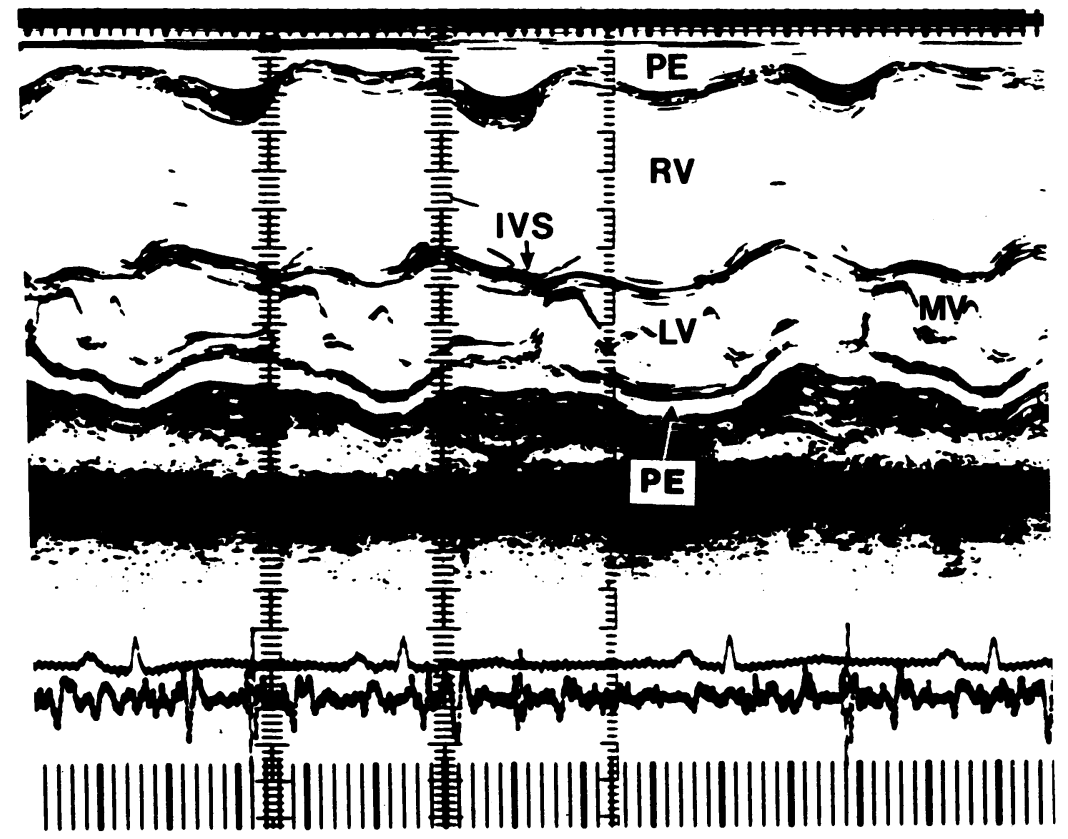

Fig. $3 M$-mode echocardiogram (case 9) showing a grossly enlarged right ventricular cavity, paradoxical septal motion, and a small left ventricular cavity. The mitral valve movement appears normal and there are anterior and posterior pericardial effusions. $P E$, pericardial effusion; $R V$, right ventricle; IVS, interventricular septum; $M V$, mitral valve. 


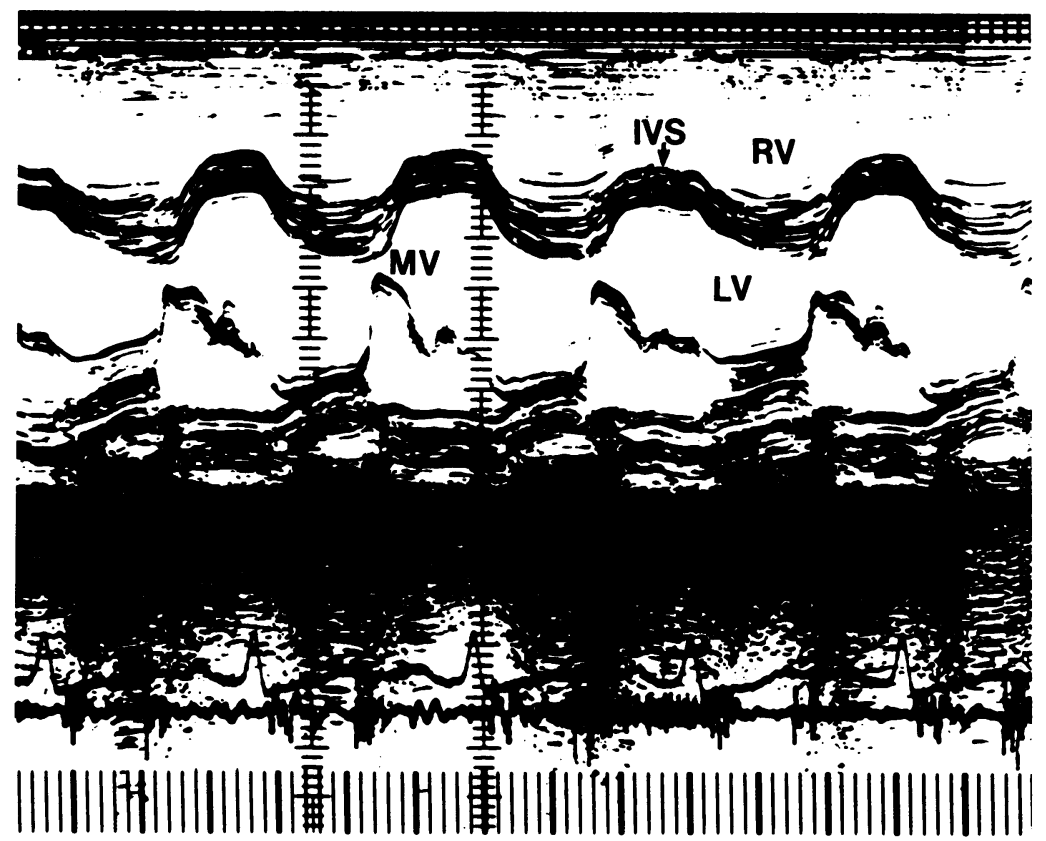

Fig. 4 An M-mode echocardiogram (case 5) showing normal septal motion with rapid anterior movement in early diastole.

in all patients studied and these are summarised in Table 4. The most striking and constant feature was the increased amplitude echoes seen in the region of the posterior mitral valve leaflet (14/15) (Fig. 6 and 7). Another frequent area of increased echo amplitude was the apex of the right ventricle (14/15) (Fig. 8). Abnormal echo intensities were also found in the anterior wall of the right ventricle (10/15) (Fig. 8 and 9 ), the posterior wall of the left ventricle $(9 / 15)$
(Fig. 10), apex of the left ventricle (6/15), and septum (4/15) (Fig. 9). Increased amplitude echoes were rarely seen in the outflow tracts of both left and right ventricles.

\section{Discussion}

All patients studied showed striking echocardiographic abnormalities reflecting specific pathological

Table 3 Summary of digitised $M$-mode echocardiograms in 15 patients with endomyocardial fibrosis

\begin{tabular}{|c|c|c|c|c|c|c|c|c|}
\hline \multirow[t]{2}{*}{$\begin{array}{l}\text { Case } \\
\text { No. }\end{array}$} & \multirow{2}{*}{$\begin{array}{l}\text { Peak velocity of } \\
\text { circumferential fibre } \\
\text { shortening (per second) }\end{array}$} & \multirow[t]{2}{*}{$\begin{array}{l}\text { Fractional } \\
\text { shortening (\%) }\end{array}$} & \multirow[t]{2}{*}{$\begin{array}{l}\text { Peak rate of filling } \\
(\mathrm{cm} / \mathrm{s})\end{array}$} & \multirow[t]{2}{*}{$\begin{array}{l}\text { Duration of rapid } \\
\text { filling ( } m s \text { ) }\end{array}$} & \multicolumn{2}{|c|}{ Diameters $(\mathrm{cm})$} & \multicolumn{2}{|c|}{$\begin{array}{l}\text { Rate of thickening and } \\
\text { thinning }(\mathrm{cm} / \mathrm{s})\end{array}$} \\
\hline & & & & & $\begin{array}{l}\text { End- } \\
\text { systole }\end{array}$ & $\begin{array}{l}\text { End- } \\
\text { diastole }\end{array}$ & Systole & Diastole \\
\hline \multirow[t]{2}{*}{$\begin{array}{c}1 \\
2 \\
3 \\
4 \\
5 \\
6 \\
7 \\
8 \\
9 \\
10 \\
11 \\
12 \\
13 \\
14 \\
15 \\
\text { Normal } \\
\text { range }\end{array}$} & $\begin{array}{l}2.3 \\
4.0 \\
4.3 \\
4.5 \\
3.2 \\
1.0 \\
2.2 \\
3.3 \\
3.8 \\
4.0 \\
3.0 \\
4.0 \\
3.1 \\
5.5 \\
2.8\end{array}$ & $\begin{array}{l}26 \\
49 \\
36 \\
44 \\
27 \\
12 \\
35 \\
43 \\
26 \\
50 \\
39 \\
38 \\
33 \\
48 \\
34\end{array}$ & $\begin{array}{r}15 \\
14 \\
9 \\
8 \\
8 \\
13 \\
14 \\
15 \\
10 \\
9 \\
10 \\
7 \\
10 \\
13 \\
15\end{array}$ & $\begin{array}{r}80 \\
160 \\
100 \\
120 \\
160 \\
160 \\
120 \\
130 \\
150 \\
160 \\
110 \\
200 \\
117 \\
200 \\
100\end{array}$ & $\begin{array}{l}1.7 \\
2.0 \\
1.9 \\
1.3 \\
1.9 \\
5.8 \\
4.7 \\
1.3 \\
2.1 \\
1.2 \\
3.0 \\
1.3 \\
1.5 \\
1.6 \\
2.6\end{array}$ & $\begin{array}{l}2.3 \\
3.9 \\
2.7 \\
2.4 \\
2.7 \\
6.7 \\
6.7 \\
2.4 \\
2.9 \\
2.4 \\
4.5 \\
2.1 \\
2.0 \\
2.8 \\
3.9\end{array}$ & $\begin{array}{l}3.0 \\
3.0 \\
4.0 \\
4.0 \\
5.5 \\
4.0 \\
5.5 \\
3.5 \\
3.0 \\
3.0 \\
4.0 \\
5.0 \\
3.0 \\
4.0 \\
4.0\end{array}$ & $\begin{array}{r}5.0 \\
5.0 \\
7.5 \\
5.0 \\
6.5 \\
11.0 \\
6.5 \\
6.0 \\
5.0 \\
4.0 \\
11.0 \\
8.5 \\
4.0 \\
5.0 \\
10.0\end{array}$ \\
\hline & $2-3$ & 33 & $12-20$ & $160-220$ & $2 \cdot 0-3 \cdot 6$ & $2 \cdot 8-4 \cdot 5$ & $4 \cdot 6 \pm 1 \cdot 2$ & $10.7 \pm 1.7$ \\
\hline \multicolumn{2}{|c|}{$\begin{array}{l}\text { No. } \\
\text { abnormal } 1 / 15\end{array}$} & $4 / 35$ & $8 / 15$ & $9 / 15$ & $\uparrow_{9 / 15}^{2 / 15}$ & $\uparrow_{9 / 15}^{2 / 15}$ & $5 / 15$ & $12 / 15$ \\
\hline
\end{tabular}




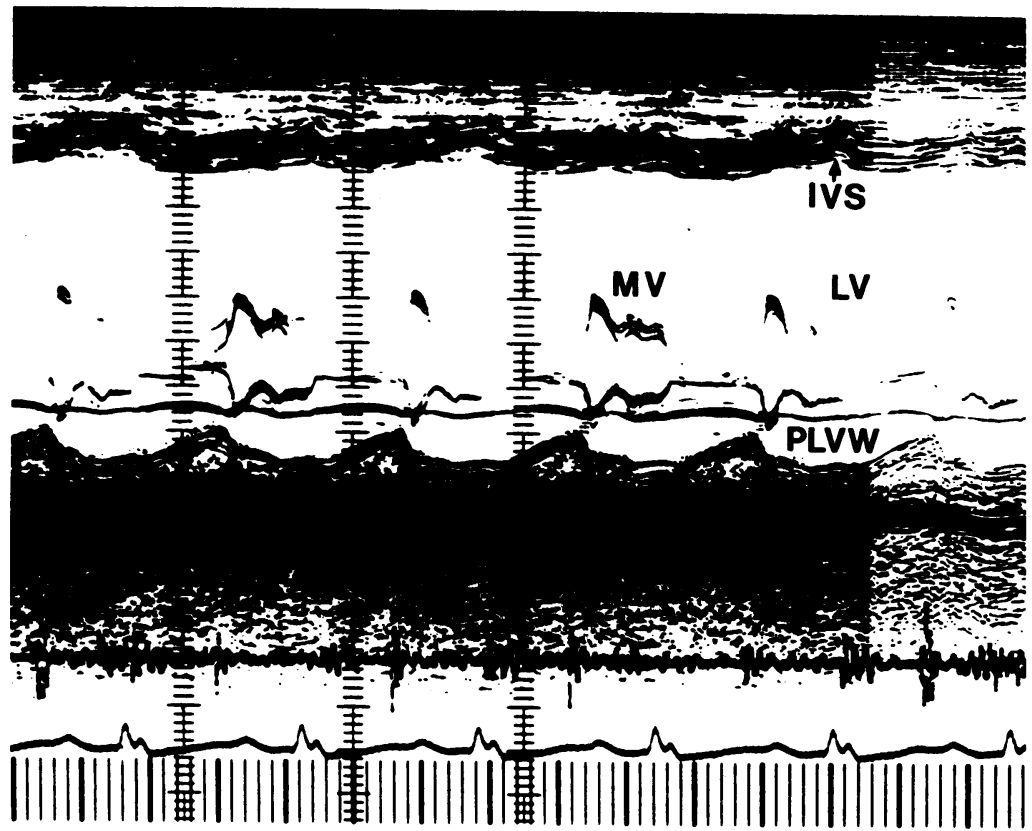

Fig. 5 An M-mode echocardiogram (case 12) showing a dilated left ventricular cavity with posterior displacement of the mitral valve apparatus and very reduced movement of the interventricular wall. PLVW, posterior left ventricular wall.

Table 4 Summary of amplitude processed cross-sectional echocardiograms in 15 patients with endomyocardial fibrosis

\begin{tabular}{|c|c|c|c|c|c|c|c|c|}
\hline \multirow{2}{*}{$\begin{array}{l}\text { Case } \\
\text { No. }\end{array}$} & \multicolumn{2}{|l|}{ Seprom } & \multirow{2}{*}{$\begin{array}{l}\text { Posterior lefi ventricular } \\
\text { wall }\end{array}$} & \multirow[t]{2}{*}{ Papillary muscles } & \multicolumn{2}{|c|}{ Mitral cusps } & \multicolumn{2}{|c|}{ Ventricle apex } \\
\hline & Apical & Basal & & & Anterior & Posterior & $L$ & $\boldsymbol{R}$ \\
\hline \multirow[t]{2}{*}{$\begin{array}{c}1 \\
2 \\
3 \\
4 \\
5 \\
6 \\
7 \\
8 \\
9 \\
10 \\
11 \\
12 \\
13 \\
14 \\
15 \\
\text { Normal } \\
\text { range } \\
\text { No. }\end{array}$} & $\begin{array}{l}40 \\
65 \\
30 \\
30 \\
35 \\
35 \\
40 \\
40 \\
35 \\
30 \\
30 \\
45 \\
60 \\
40 \\
35\end{array}$ & $\begin{array}{l}40 \\
65 \\
30 \\
30 \\
35 \\
35 \\
40 \\
60 \\
35 \\
30 \\
30 \\
45 \\
60 \\
40 \\
35\end{array}$ & $\begin{array}{l}50 \\
60 \\
55 \\
30 \\
30 \\
30 \\
60 \\
45 \\
60 \\
30 \\
30 \\
30 \\
45 \\
45 \\
35\end{array}$ & $\begin{array}{l}45 \\
60 \\
40 \\
35 \\
90 \\
35 \\
35 \\
30 \\
30 \\
30 \\
60 \\
30 \\
45 \\
40\end{array}$ & $\begin{array}{l}40 \\
\frac{40}{30} \\
\frac{-}{40} \\
35 \\
60 \\
40 \\
30 \\
35 \\
45 \\
60 \\
-\end{array}$ & $\begin{array}{l}60 \\
95 \\
70 \\
60 \\
60 \\
60 \\
60 \\
55 \\
60 \\
60 \\
60 \\
90 \\
60 \\
45 \\
70\end{array}$ & $\begin{array}{l}40 \\
65 \\
90 \\
25 \\
90 \\
40 \\
30 \\
30 \\
= \\
30 \\
50 \\
45 \\
\frac{60}{60}\end{array}$ & $\begin{array}{l}55 \\
90 \\
90 \\
60 \\
80 \\
50 \\
45 \\
60 \\
60 \\
45 \\
60 \\
60 \\
50 \\
60\end{array}$ \\
\hline & \multicolumn{2}{|c|}{$25-40$} & $17-30$ & $30-40$ & $20-50$ & & $25-40$ & $25-40$ \\
\hline abnormal & $3 / 15$ & $4 / 15$ & $9 / 15$ & $5 / 15$ & $2 / 15$ & $14 / 15$ & $6 / 15$ & $14 / 15$ \\
\hline
\end{tabular}




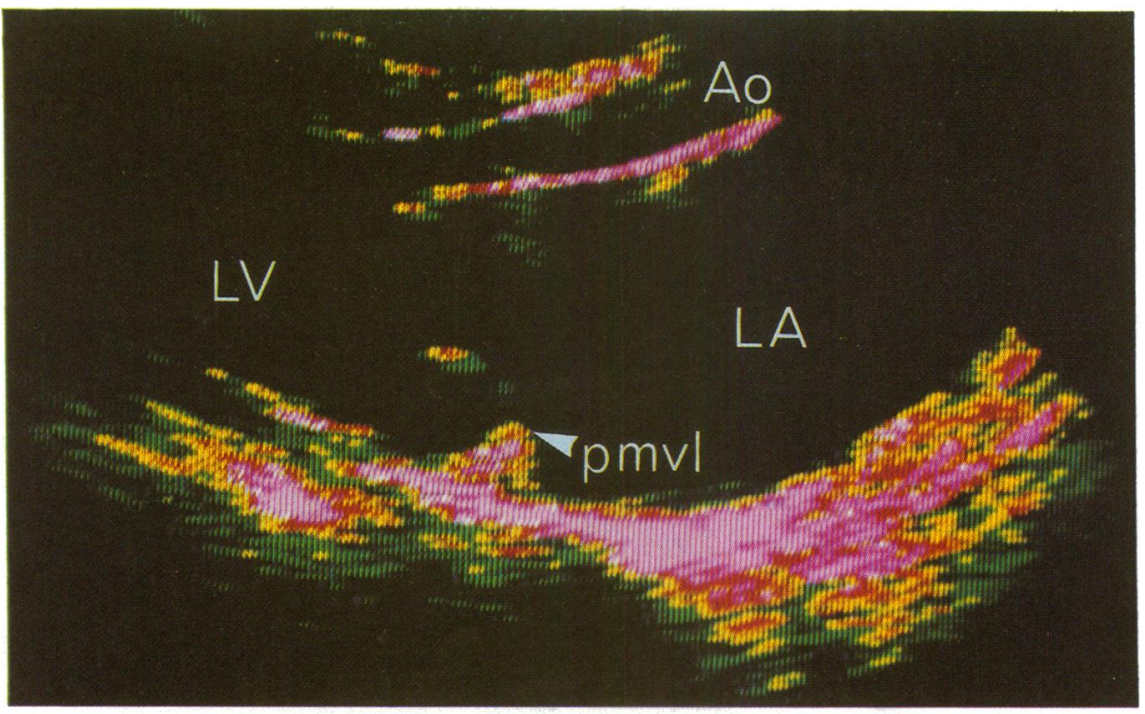

Fig. 6 Parasternal long axis view, processed image (case 5), showing echoes of increased amplitude reflecting from the posterior left ventricular wall, particularly in the area of attachment of the posterior mitral valve leaflet (pmvl). There appears to be a "lump" of increased echo amplitude in this region.

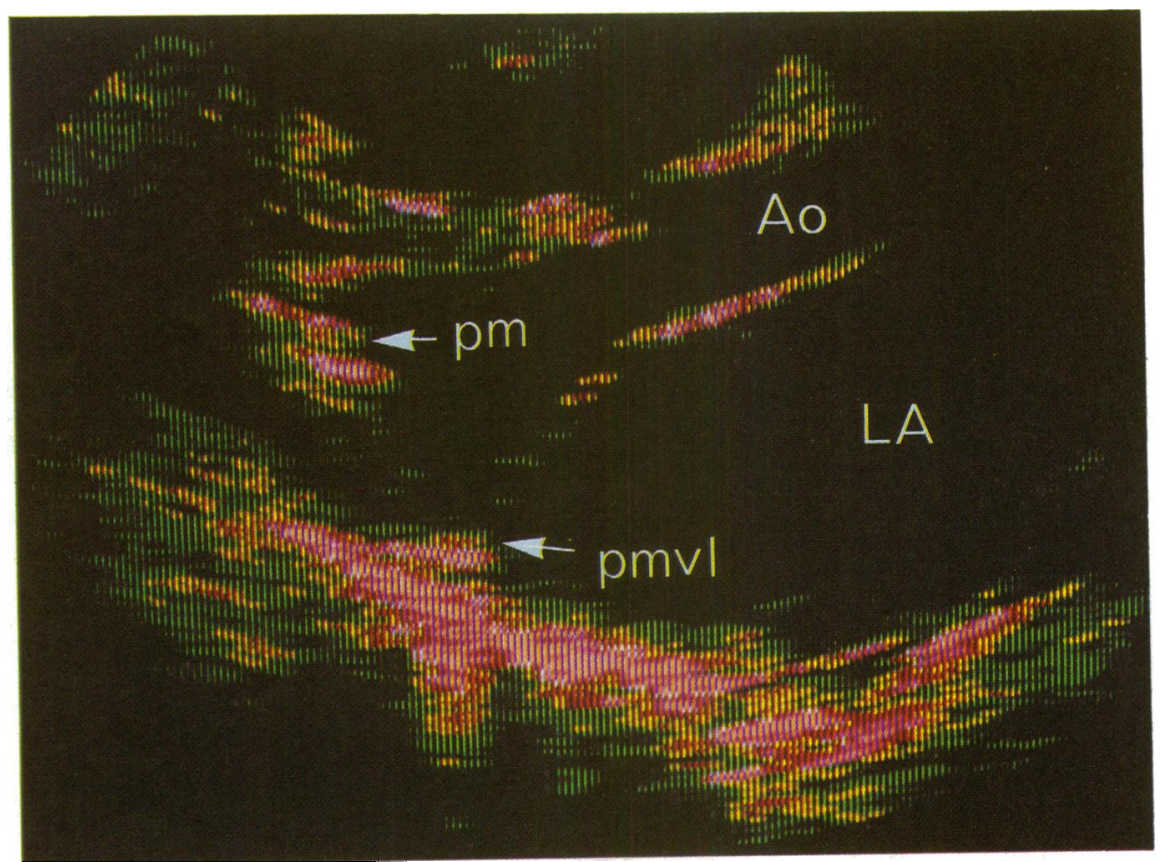

Fig. 7 Parastermal long axis view, processed image (case 8) showing echoes of increased intensity returning from the posterior left ventricular wall, particularly in the region of the posterior mitral valve leaflet (pmvl). Increased amplitude echoes can also be seen returning from the cavity of the left ventricle probably coming from thickened papillary muscles (pm). 


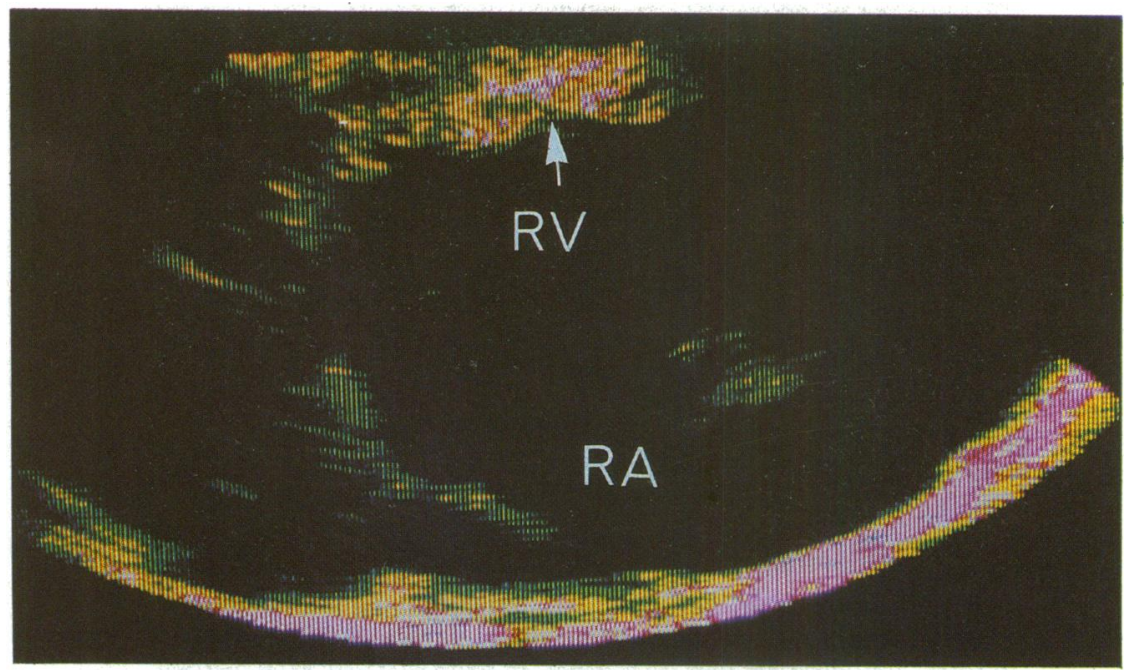

Fig. 8 Apical two chamber view of the right side of the heart (case 7), processed image, showing a grossly dilated right ventricle $(R V)$ and right atrium $(R A)$, with echoes of increased amplitude reflected from the apex of the right ventricle (arrow).

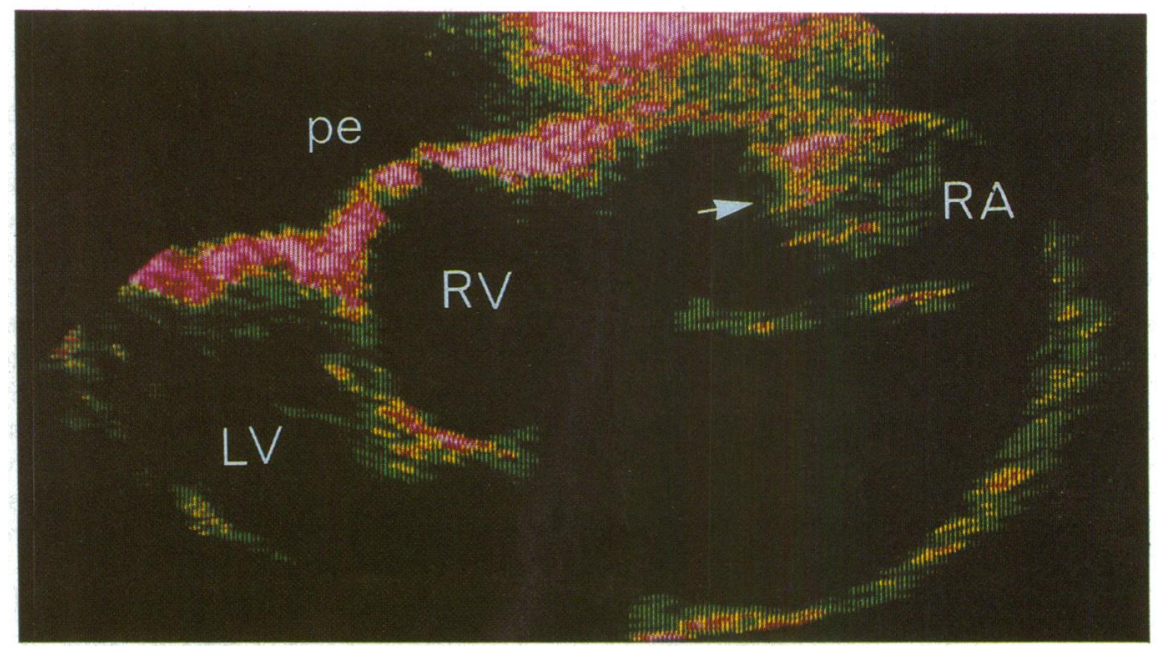

Fig. 9 Epigastric four chamber view, processed image (case 9), showing extensive areas of increased echo amplitude over the apices of both right and left ventricles with "dimple" well seen. There is a large pericardial effusion (pe). The right ventricle and right atrium appear grossly enlarged and there is a right atrial thrombus (arrow). 


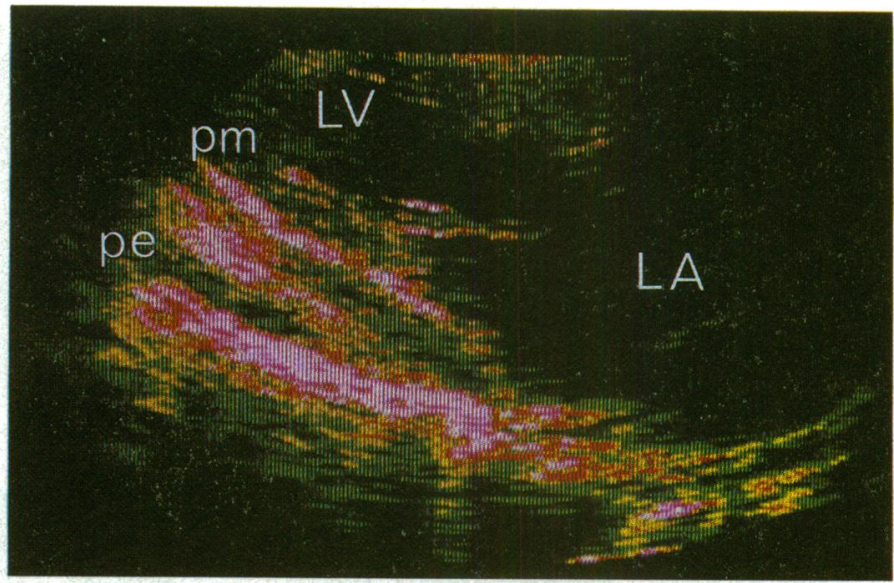

Fig. 10 Parastemal long axis view, processed image (case 11), showing an expanded view of the posterior left ventricular wall. Note the two layers of increased echo amplitude over the posterior left ventricular wall extending into the posterior papillary muscles (pm). There is a small pericardial effusion (pe).

features of endomyocardial fibrosis, and suggested that this technique alone could be used to diagnose endomyocardial fibrosis non-invasively during life. Cross-sectional echocardiography using a standard grey scale display showed localised areas of echo dense material on the posterior left ventricular wall in the region of the posterior mitral valve leaflet in all patients. In many patients movement of the posterior mitral valve leaflet appeared to be restricted. This appearance corresponded well to the tethering of this leaflet known to occur pathologically. Identical findings have been reported in echocardiographic studies of patients with endomyocardial fibrosis investigated in other countries 71314 and this crosssectional abnormality appears to be specific for this disease. Cross-sectional echocardiography was also useful in identifying intracavity thrombus in some patients (Fig. 9). Colour coding of regional echo amplitude showed that in all patients high intensity echoes were detected whose distribution corresponded closely to that of the fibrosis known to occur in this disease. ${ }^{15}$ Such echoes were identified in almost every case in the posterior mitral valve leaflet and less frequently over the posterior left ventricular wall near the base of the papillary muscle, the apex of the left ventricle, and the lower part of the intraventricular septum. With severe right ventricular disease, the anterior wall of the right ventricle contracted poorly and frequently reflected high amplitude echoes. A "dimple" could be identified on the anterior wall corresponding to the fibrous retraction of the apex of the right ventricle, known to occur pathologically15 (Fig. 9). Though high amplitude echo images were well seen in the inflow portion of both ventricles, the apical portion of the frequently paradoxically moving interventricular septum reflected low amplitude echoes similar to normal endomyocardium. These results support the available experimental and clinical evidence suggesting that collagen has a greater capacity than normal myocardium to reflect ultrasound. ${ }^{16} 17$

M-mode abnormalities reported by previous authors ${ }^{2-7}$ were confirmed in the present study. They were non-specific and frequently related to right ventricular enlargement and volume overload. In particular, posterior wall thickness was increased in only four patients contrary to previous reports, ${ }^{18}$ indicating that this measurement is not a good guide to the presence or severity of endomyocardial fibrosis. A characteristic finding on $\mathbf{M}$-mode, particularly in children, was a small, sometimes unmeasurable, left atrial cavity, possibly because massive right atrial and ventricular enlargement had caused the heart to rotate.

Although digitisation of $\mathbf{M}$-mode echocardiograms did not contribute any specific diagnostic information, it was helpful in defining physiological disturbances occurring in this condition. Systolic function appeared to be well preserved in most patients. High peak rates of circumferential fibre shortening were found in patients with clinically severe mitral regurgitation. Diastolic abnormalities were common and included a reduction in the peak rate of filling and the shortening of the duration of rapid filling. The reduction of the rate of diastolic thinning found in the majority of patients is not surprising in the presence of extensive endomyocardial fibrosis. This, in combination with shortening of the duration of the period of rapid filling and reduction in end-diastolic diam- 
eter, defines the "restrictive" element to left ventricular filling caused by endomyocardial fibrosis.

There were thus many similarities between the echocardiographic features of this disease as it occurs in tropical and temperate regions, both in the distribution of increased amplitude echoes affecting the posterior left ventricular wall and more particularly the posterior mitral valve leaflet. A number of differences, however, could be defined. The very severe right sided form of this disease that occurs in India, with echocardiographic changes related to right ventricular volume overload and/or aneurysmal right atrial enlargement, was not so frequently seen in England. ${ }^{7}$ Apical involvement of either ventricle was seen much more commonly in India. Finally, a restrictive pattern of left ventricular filling was not seen in patients with endomyocardial fibrosis from temperate regions. ${ }^{7}$

Cross-sectional echocardiography, particularly when supplemented by colour coded amplitude processing, can thus be used to make a confident diagnosis of endomyocardial fibrosis during life. $M$-mode echocardiography, particularly with digitisation, provides additional information on left ventricular systolic and diastolic function. It is hoped that this non-invasive technique will prove useful in following the progress or assessing the effect of treatment on the course of this disease.

We are grateful to the Wellcome Trust for their generous financial support, the British Council for help in organisation, Dr K V Korrah (Principal, Medical College, Trivandrum), and Dr S Potti (Professor of Cardiology, Medical College, Trivandrum) for their help and co-operation in setting up this study. The work was carried out under the auspicies of the International Society and Federation of Cardiology.

\section{References}

1 World Health Organisation Report of the WHO/ISFC task force on the definition and classification of cardiomyopathies. $\mathrm{Br}$ Heart $\mathcal{F}$ 1980; 44: 672-3.

2 Dienot B, Ekra A, Bertrand E. L'échocardiographie dans 23 cas de fibroses endomyocardiques constrictives droites ou bilatérales. Arch Mal Coeur 1979; 72: 1101-7.

3 Haertel JG, Castro I. Avaliaçao ecocardiográfica da fibrose endomiocárdica. Arq Bras Cardiol 1980; 35: 47580.

4 Pernod J, Gerbaux A, Vervin P, Terdjman M, Lelguen C, Droniou J. Apport de l'échocardiographie dans le diagnostic des fibroses endomyocardiques. Arch Mal Coeur 1980; 73: 139-46.

5 Hess OM, Turina M, Senning A, Goebel NH, Scholer Y, Krayenbuehl HP. Pre- and postoperative findings in patients with endomyocardial fibrosis. Br Heart $\mathcal{f}$ 1978; 40: 406-15.

6 Chew CYC, Ziady GM, Raphael MJ, Nellen M, Oakley CM. Primary restrictive cardiomyopathy. Non-tropical endomyocardial fibrosis and hypereosinophilic heart disease. $B r$ Heart $\mathcal{f}$ 1977; 39: 399-413.

7 Davies J, Gibson DG, Foale R, et al. Echocardiographic features of eosinophilic endomyocardial disease. Br Heart f 1982; 48: 434-40.

8 Feigenbaum H. Echocardiography. 2nd ed. Philadelphia: Lea \& Febiger, 1976: 464.

9 Upton MT, Gibson DG. The study of left ventricular function from digitized echocardiograms. Prog Cardiovasc Dis 1978; 20: 359-84.

10 Gibson DG, Brown D. Measurement of instantaneous left ventricular dimension and filling rate in man, using echocardiography. Br Heart f 1973; 35: 1141-9.

11 Tajik AJ, Seward JB, Hagler DJ, Mair DD, Lie JT. Two-dimensional real-time ultrasonic imaging of the heart and great vessels: technique, image orientation, structure identification, and validation. Mayo Clin Proc 1978; 53: 271-303.

12 Logan-Sinclair R, Wong CM, Gibson DG. Clinical application of amplitude processing of echocardiographic images. Br Heart $\mathcal{F}$ 1981; 45: 621-7.

13 Gottdiener JS, Maron BJ, Schooley RT, Harley JB, Roberts WC, Fauci AS. Two-dimensional echocardiographic assessment of the idiopathic hypereosinophilic syndrome. Circulation 1983; 67: 5728.

14 Acquatella H. Two-dimensional echocardiography in endomyocardial disease. Postgrad Med F 1983; 59: 157-8.

15 Olsen EGJ. Cardiomyopathies. Cardiovasc Clin 1972; 4: 239-61.

16 Chivers RC. Tissue characterization. Ultrasound Med Biol 1981; 7: 1-20.

17 Gibson DG, Logan-Sinclair RB, Shaw TRD, et al. Relation between regional echo intensity and myocardial connective tissue in left ventricular disease [Abstract]. Circulation 1982; 66 (suppl II): 29.

18 Parrillo JE, Borer JS, Henry WL, Wolff SM, Fauci AS. The cardiovascular manifestations of the hypereosinophilic syndrome. Am f Med 1979; 67: 572-82.

Requests for reprints to Dr J Davies, Royal Gwent Hospital, Newport, Gwent NP4 0YP. 